Annals of Tropical Research 30(1):1-14 (2008)

○ VSU, Leyte, Philippines

\title{
In vitro plant regeneration from flower stalk explants of Phalaenopsis amabilis (L.) BI.
}

\author{
Darlyn B. Posas and Marilyn M. Belarmino \\ Department of Horticulture, Visayas State University, \\ Visca, Baybay City, Leyte, 6521-A Philippines
}

\begin{abstract}
An in vitro method was developed for plant regeneration of Phalaenopsis amabilis variety and hybrid using flower stalk cuttings. Experiments were conducted to overcome persistent contamination of stalks, break bud dormancy and induce regeneration of shoots. Results showed that incorporating $50 \mathrm{mg} / 1$ streptomycin in agar-solidified Vacin and Went (VW) medium inactivated or killed fungal and bacterial microorganisms that may have been left after sterilizing the stalks with $95 \%$ ethyl alcohol and $20 \%$ chlorine bleach. The stalk explants cultured in VW medium added with $5 \mathrm{mg} / \mathrm{l}$ benzylamino purine broke bud dormancy and induced the regeneration of shoots. The regenerated shoots exhibited three growth patterns, namely; vegetative, reproductive and dormant. The vegetative shoot produced multiple adventitious shoots in VW medium containing a combination of $5 \mathrm{mg} / \mathrm{l}$ benzylamino purine and $0.1 \mathrm{mg} / \mathrm{l}$ indole acetic acid. The regenerated shoots resembled the source plants and rooted easily in plant growth regulator-free medium. These were established in the screenhouse after acclimatization. The vegetative shoot has potential for clonal propagation of Phalaenopsis species.
\end{abstract}

Keywords: adventitious shoot, benzylamino purine, bud emergence, shoot formation

Correspondence: M.M. Belarmino. Department of Horticulture, College of Agriculture, Visayas State University, Baybay City, Leyte, 6521-A Philippines. E-mail: lyn3063@yahoo.com. Tel. No. (053) 335 2628; Fax No. (053) 3352601

DOI: 10.32945/atr3011.2008 


\section{INTRODUCTION}

Phalaenopsis is one of the popular orchid genera grown commercially for cutflowers and pot plants. Neele (1993) estimated the total demand for cutflowers in the Philippines was 9.36 M dozen with $1.65 \mathrm{M}$ dozen from orchids. Over $75 \%$ of all orchids sold in the international market are Phalaenopsis and orchid sales in year 2000 were approximately US \$100 M (Griesbach, 2002).

Phalaenopsis amabilis is one of the species that is extensively used as parent-plants in hybridization because of its large and long lasting flowers. Like many other monopodial orchids, these species do not normally form offshoot that make them difficult to propagate vegetatively (Armstrong, 2001). Propagation using seeds is not commonly practiced because of the heterozygous characteristics of seedlings hence, propagation through tissue culture has been suggested. Also, improvement of Phalaenopsis through genetic transformation has been done employing regeneration and tissue culture protocols (Belarmino and Mii, 2000).

Several tissue culture techniques have been developed for Phalaenopsis orchids, including the culture of flower stalks with axillary buds, meristems, internodal segments of flower stalks (Arditti and Earnst, 1993; Park et al.,1996), leaf segments (Park et al., 2002; Ishii et al., 1998) and root tips (Arditti and Ernst, 1993; Ichihashi, 1997). Among these techniques, the flower stalk culture is an excellent method for rapid clonal propagation (Tanaka, 1992; Tokuhara and Mii, 1993) since the parent plant is not harmed and can grow normally after the stalks are harvested. Also, direct shoot regeneration without undesirable callus formation shortens the time period needed to produce plantlets and reduces the occurrence of somaclonal variants. However, reports of successful plant regeneration using flower stalks have been very limited (Arditti and Ernst, 1994; Tanaka, 1992; Tokuhara and Mii, 1993). Most of these studies reported variable culture response and propagation rate due to differences in pretreatment of donor plants, cultivar specificity and culture requirements. These reports also highlighted several problems encountered in flower stalk culture of Phalaenopsis such as (1) the persistence of contaminating microorganisms (i.e., bacteria and fungi) after decontamination, (2) browning of culture medium due to phenol substances released from the detached stalk (Sarmiento, unpublished), (3) dormancy of stalk buds and, (4) slow growth of stalk-derived shoot. In the present study, 
different decontamination methods were used to obtain high percentage of aseptic flower stalk explants. Several plant growth regulators were also used to induce shoot formation from nodes of flower stalks in order to develop an efficient clonal propagation method for Phalaenopsis orchids.

\section{MATERIALS AND METHODS}

\section{Plant material}

Mature flowering plants of a local variety of Phalaenopsis amabilis with small white flowers and a hybrid named, 'Temple Cloud', with large white flowers were collected and maintained in the screenhouse. The plants were sprayed with foliar fertilizer (Siam, Sunwise Enterprises, Q.C., Philippines) at $1 / 2$ tbsp per gallon of water at 2 weeks interval and sprayed with $0.1 \%$ fungicide (i.e., Benlate, Du Point Far East Inc., Makati, Manila) once a week. After four weeks of treatment, the flower stalks were detached from the mother plant and cut into $2-\mathrm{cm}$ segments each containing a single dormant bud.

\section{Preparation of culture medium}

The VW medium (Vacin and Went, 1949) containing $30 \mathrm{mg} / \mathrm{l}$ thiamine, $20 \%$ (v/v) coconut water, $20 \mathrm{~g} / \mathrm{l}$ sugar (white refined table sugar) and solidified with $7 \mathrm{~g} /$ l agar-agar (Pronadisa Hispanlab, Madrid, Spain) was designated as the basal medium (Tanaka 1992) and used throughout the study. The $\mathrm{pH}$ of the culture medium was adjusted to 5.7 to 5.8 using $0.1 \mathrm{~N} \mathrm{NaOH}$ or $0.1 \mathrm{~N}$ $\mathrm{HCl}$ before dispensing at $10 \mathrm{ml}$ volume into glass vials with plastic caps. The medium was autoclaved at $15 \mathrm{psi}$ for $15-20 \mathrm{~min}$ and allowed to cool before use.

\section{Surface sterilization of flower stalk explants}

Flower stalk cuttings from preconditioned donor plants were subjected to three decontamination treatments to remove microbial contaminants. In treatment 1 , the flower stalks with dormant bud were cut into 4-cm length and quickly immersed in $95 \%$ ethyl alcohol. Inside the laminar flow hood, this 
solution was decanted and replaced with $20 \%$ commercial bleaching solution (i.e. Zonrox containing $4.5 \%$ active chlorine) added with 2 - 3 drops of Tween 20 . After $20 \mathrm{~min}$, the solution was decanted and the stalks were rinsed three times with sterile distilled water. The decontaminated stalk explants were blotted dry on sterile paper and the bracts covering the bud were carefully removed. The stalk explants were further soaked in $10 \%$ Zonrox solution for $10 \mathrm{~min}$ then, the solution was decanted and the stalks were rinsed three times with sterile distilled water. Finally, the decontaminated stalk explants were trimmed to $1.0-1.5 \mathrm{~cm}$ length. In Treatment 2 , the stalk cuttings were subjected to $95 \%$ ethyl alcohol and $20 \%$ Zonrox solution just like in Treatment 1 . However, after the stalks were blotted dry, the buds $(\sim 5 \mathrm{~mm})$ were excised. In Treatment 3 , the stalk cuttings after pretreatment with $95 \%$ ethyl alcohol were treated just like Treatment 1 except, that the stalk explants were inoculated in agar-solidified VW medium supplemented with $25 \mathrm{mg} / \mathrm{l}$ streptomycin (Zigma).

All stalk explants were inoculated individually into vials $(95 \mathrm{~mm} \times 28$ $\mathrm{mm}$ ) containing $10 \mathrm{ml}$ of agar-solidified VW medium containing $20 \mathrm{~g} / \mathrm{l}$ sucrose, $30 \mathrm{mg} / \mathrm{l}$ thiamine, $20 \%(\mathrm{v} / \mathrm{v})$ coconut water and $5 \mathrm{mg} / \mathrm{l}$ benzylamino purine (BAP). These were incubated under $16 \mathrm{~h}$ daylight provided by $40-\mathrm{W}$ cool white fluorescent tubes (Philips, Philips Electronic \& Lighting, Inc.) at $25 \pm 1$ ${ }^{\circ} \mathrm{C}$ unless, otherwise stated. The percentages of aseptic and viable flower stalk explants obtained from each treatment were assessed after 3 weeks of culture. The most effective decontamination method was used in the succeeding experiments.

\section{Initial culture of flower stalk explants}

Decontaminated flower stalk explants $(\sim 1.0-1.5 \mathrm{~cm}$ long) were inoculated in agar-solidified VW medium (initiation medium) to break bud dormancy and induce shoot formation. This medium was supplemented with $\mathrm{BAP}$ at $5 \mathrm{mg} / \mathrm{l}(\mathrm{T} 1)$ or $10 \mathrm{mg} / \mathrm{l}$ (T2). The medium without BAP served as the control (T0). Twenty flower stalk explants were inoculated individually into the treatment medium and incubated under $16 \mathrm{~h}$ photoperiod at $25 \pm 1^{\circ} \mathrm{C}$. The stalk explants were transferred six times to fresh medium at 2 weeks interval to break the dormancy of lateral bud and induce shoot formation. 


\section{Multiple shoot formation from flower stalk-derived shoots}

The flower stalk bud-derived shoots obtained from the initiation medium were transferred to fresh agar-solidified VW basal medium supplemented with 2,5 , and $10 \mathrm{mg} / \mathrm{l} \mathrm{BAP}$ and $0.1 \mathrm{mg} / 1$ indole acetic acid (IAA) at all combinations to induce multiple production of adventitious shoots (proliferation medium). The medium without plant growth regulator served as control. Twenty shoots were inoculated individually into each treatment medium and incubated under the same condition used in Experiment I. After 12 weeks, adventitious shoots that were formed in clusters were separated individually and subcultured on the most effective treatment medium. The shoots were allowed to grow in this medium and further subcultured four times at two weeks interval. The percentage of shoot cultures producing multiple adventitious shoots and the number of days to multiple shoot formation were recorded in each treatment medium using fifteen shoot samples.

\section{In vitro rooting of plantlets and potting out}

Shoots $(1-2 \mathrm{~cm}$ in height) with at least two fully opened leaves were transferred in one half-strength of agar-solidified VW medium supplemented with either $1.0 \mathrm{mg} / 1$ or $5 \mathrm{mg} / \mathrm{l}$ indole butyric acid (IBA) (treatments) to induce rooting. The half-strength VW basal medium without IBA served as control. Twenty shoots were individually transferred in 100-ml capacity tin-capped glass jar (San Miguel Corp., Philippines) containing $20 \mathrm{ml}$ of rooting medium and incubated under $16 \mathrm{~h}$ photoperiod at $25 \pm 1^{\circ} \mathrm{C}$. The rooting response of shoots was recorded after 12 weeks of culture.

Flower stalk bud-derived plantlets with two or more leaves and at least two roots were acclimatized (while still inside the culture jar) by placing them at ambient room condition $\left(28-32^{\circ} \mathrm{C}\right)$ for one week prior to potting. Then, the plantlets were taken out of culture jars and the roots were washed with tap water to remove adhering agar. The roots were quickly dipped in $0.1 \%$ fungicide solution for $15 \mathrm{~min}$ to prevent fungal infection and then, the plantlets were transferred in clay thumb pots $(6 \mathrm{~cm} \times 6 \mathrm{~cm})$ containing a mixture of charcoal chips and coconut coir $(1: 1, \mathrm{v} / \mathrm{v})$. Potted plantlets were covered with transparent plastic sheet to prevent the roots from drying up and then, placed in the screen house. Hand misting was provided everyday for the first two weeks after potting and at one-day interval thereafter. Percent survival of plantlets was assessed one month after potting. 
All experiments were laid out following the completely randomized design. The treatment means were compared using Tukey, Homogeneous Subset Test.

\section{RESULTS AND DISCUSSION}

\section{Sterilization of flower stalk explants}

Incorporating streptomycin (T3) in the initial culture medium resulted to the highest percentage of aseptic stalk explants with viable buds $(66 \%)$ compared to those treated with ethyl alcohol and chlorine bleach (T1) or, buds that were excised from the flower stalk tissue (T2) (Fig. 1). The streptomycin may have inactivated or killed the fungal and bacterial microorganisms present in the crevices of the stalk surrounding the bud. Sustained growth of lateral buds was observed from T1- and T3-treated stalk explants but none from T2-excised buds. Excising the lateral buds from the stalk tissue in T2 exposed the buds to the sterilizing solutions that caused severe damage or death of the buds. Likewise, the production of shoots other than those originating from the dormant bud was observed only in T1-treated stalk buds and none from T3 (Fig. 1). This maybe due to the inhibitory effect of streptomycin on the growth of buds (in T3) as reported by Tanaka et al. (1992). In this experiment, it is clear that the streptomycin incorporated in the initial culture medium prevented the multiplication of bacteria. Astudy of Lopez (unpublished) using banana variety'Lakatan' revealed the effect of streptomycin in inducing early thickening and greening of the shoot tip explant of banana variety Lakatan that resulted to faster shoot emergence. However, inhibitory effect of streptomycin was observed in the succeeding culture phase with low percentage of plantlets reaching micropropagation stage.

\section{Influence of BAP breaking bud dormancy and shoot regeneration}

Results presented in Table 1 showed variable responses of $P$. amabilis variety and hybrid to BAP. The stalk buds from the local variety broke 
In vitro plant regeneration of Phalaenopsis amabilis (L.) Bl.

Table 1. Effect of BAP on bud break and shoot formation from flower stalk explants of P. amabilis and "Temple Cloud" at 3 and 6 months after inoculation

\begin{tabular}{llllll}
\hline Cultivar & $\begin{array}{l}\text { BAP Level } \\
(\mathrm{mg} / \mathrm{l})\end{array}$ & $\begin{array}{l}\text { Ave. no. of } \\
\text { days to bud } \\
\text { emergence }\end{array}$ & $\begin{array}{l}\text { Ave. no. of } \\
\text { days to shoot } \\
\text { formation }\end{array}$ & $\begin{array}{l}\text { Ave. no. of } \\
\text { shoots per } \\
\text { explants after } \\
\text { 3 mos. }\end{array}$ & $\begin{array}{l}\text { Ave. no. of } \\
\text { shoots per } \\
\text { explant } \\
\text { after 6 mos }\end{array}$ \\
\hline & 0 & 10.8 & 26.8 & 0.8 & 0.8 \\
Local & 5BAP & 10.2 & 40.2 & 2.2 & 3.8 \\
Variety & $10 \mathrm{BAP}$ & 14.9 & 44.4 & 1.3 & 1.2 \\
& & & & & 0.8 \\
Hybrid & 0 & 29.1 & 48.2 & 0.8 & 2.4 \\
"Temple & 5BAP & 18.4 & 32.3 & 1.8 & 2.4 \\
Cloud" & 10BAP & 20.1 & 35.8 & 1.5 & \\
\hline
\end{tabular}

Means in a column having a common letter are not significantly different at 0.05 level according to Tukey, HSD Test

dormancy after an average of 10.2 to 14.9 days (Fig. 2A) whereas, those from the hybrid 'Temple Cloud' was after 18.4 to 29.1 days (Fig. 2B). The local variety did not require BAP for bud emergence whereas, the hybrid needed at least $5 \mathrm{mg} / 1 \mathrm{BAP}$ to expedite bud emergence (Table 1). This is probably due to the difference in bud size between the variety and hybrid. It was noticeable that the flower stalk buds of the local variety were more prominent compared to the hybrid 'Temple Cloud'. Though the latter has a larger stalk diameter, the bud was not well developed indicating that conspicuous and well developed buds grew earlier than the small ones.

Generally, BAP-enriched medium shortened the period for shoot emergence by 11 days compared to the BAP-free medium. BAP at $5 \mathrm{mg} / \mathrm{l}$ was sufficient to initiate bud emergence and $10 \mathrm{mg} / 1$ was no longer beneficial. The favorable effect of BAP in inducing the sprouting of buds was also reported by Tanaka (1992). The breaking of bud dormancy was followed by the growth of the bud into a shoot. Interestingly, delayed shoot initiation of the flower stalk bud was observed in $P$. amabilis variety. This was attributed to the thickening of basal portion of buds and de novo production of adventitious shoots. In contrast, the hybrid 'Temple Cloud' responded favorably to BAP 


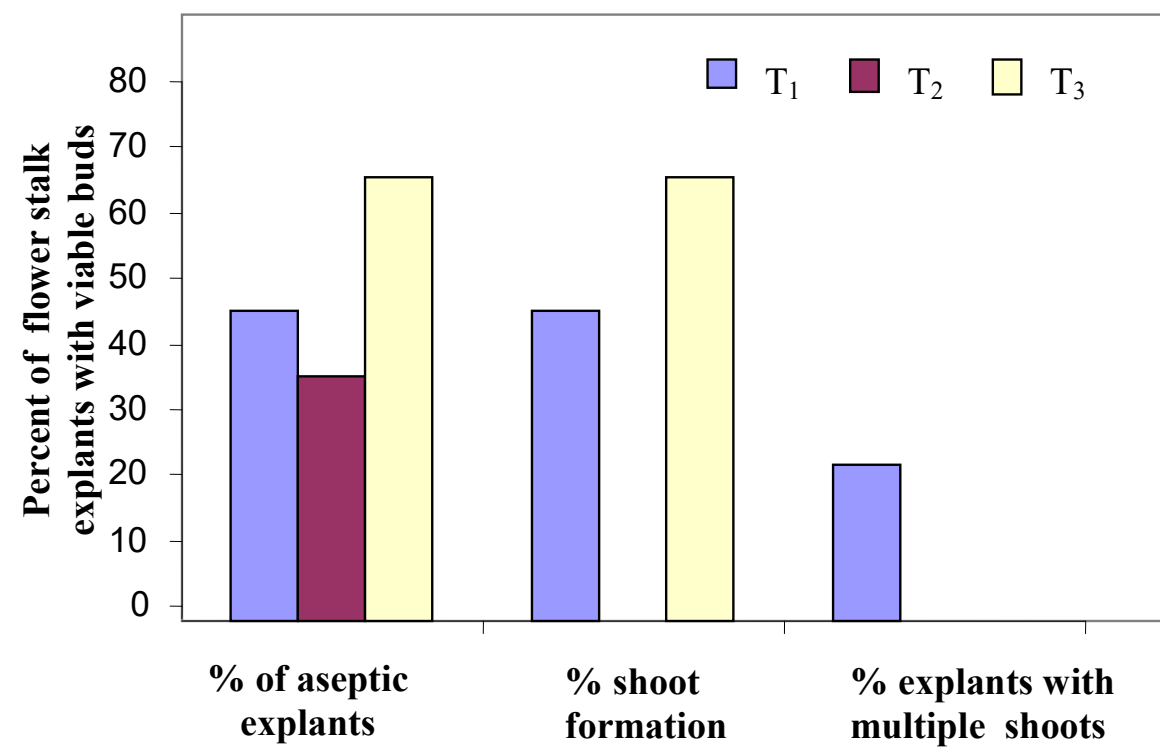

Figure 1. Sterilization of treatments of P. amabilis flower-stalk explant. $\mathrm{T}_{1}$ - ethyl alcohol and chlorine bleach; $\mathrm{T}_{2}$ - ethyl alcohol and chlorine bleach with bud excision and; and $\mathrm{T}_{3}$ - ethyl alcohol \& chlorine bleach with streptomycin incorporated in medium. 
In vitro plant regeneration of Phalaenopsis amabilis (L.) BI.

Table 2. Shoot formation and growth patterns of P. amabilis and "Temple Cloud" flower stalk buds on agar-solidified VW medium contaning $20 \mathrm{~g} / \mathrm{L}$ sucrose, $30 \mathrm{mg} / \mathrm{L}$ thiamine and different levels of BAP

\begin{tabular}{|c|c|c|c|c|c|}
\hline \multirow[t]{2}{*}{ Cultivar } & \multirow[t]{2}{*}{$\begin{array}{l}\text { BAP Level } \\
(\mathrm{mg} / \mathrm{L})\end{array}$} & \multirow{2}{*}{$\begin{array}{l}\text { Shoot } \\
\text { formation } \\
(\%)\end{array}$} & \multicolumn{3}{|c|}{$\begin{array}{l}\text { Percentage of shoots with specific } \\
\text { growth patterns }\end{array}$} \\
\hline & & & Vegetative & Reproductive & Dormant \\
\hline \multirow[t]{3}{*}{ Local Variety } & 0 & 75 & 75 & 0 & 25 \\
\hline & $5 \mathrm{BAP}$ & 95 & 80 & 15 & 5 \\
\hline & 10BAP & 90 & 85 & 5 & 10 \\
\hline \multicolumn{6}{|l|}{ Hybrid } \\
\hline \multirow[t]{3}{*}{ "Temple Cloud" } & 0 & 75 & 75 & 0 & 25 \\
\hline & $5 \mathrm{BAP}$ & 95 & 70 & 25 & 5 \\
\hline & 10BAP & 100 & 85 & 15 & 0 \\
\hline
\end{tabular}

treatment by hastening shoot formation compared to the BAP-free medium or, control (Table 1).

An average of 2.2 and 1.8 shoots were produced from one flower stalk bud of $P$. amabilis variety and hybrid, respectively, in medium containing 5 mg/l BAP(Table 1). This number increased after 6 months of culture in the same medium. Contrastingly, there was no formation of adventitious shoot in the medium lacking BAP or control. Multiple shoot formation was higher in the local variety (70\%) compared to the hybrid 'Temple Cloud' (35\%). The same trend was observed after 6 months.

Furthermore, three growth patterns of lateral buds were observed in $P$. amabilis variety and hybrid, namely; (1) they remained dormant, (2) they grew to form vegetative shoots and, (3) grew to form secondary flower stalks. The vegetative pattern was characterized by the usual production of leaves (Fig. 2C). The reproductive pattern on the other hand, was marked by the formation of an elongated structures sometimes referred as second inflorescence (Fig. 2D). These growth patterns were mentioned in the works of Urata and Iwanaga (1965); Koch (1974a, b) as cited by Tanaka (1992). In the BAP-free medium or control, all regenerated shoots $(75 \%)$ showed vegetative growth pattern (Table 2 ). With the addition of $5 \mathrm{mg} / \mathrm{l} \mathrm{BAP,} \mathrm{70-}$ 

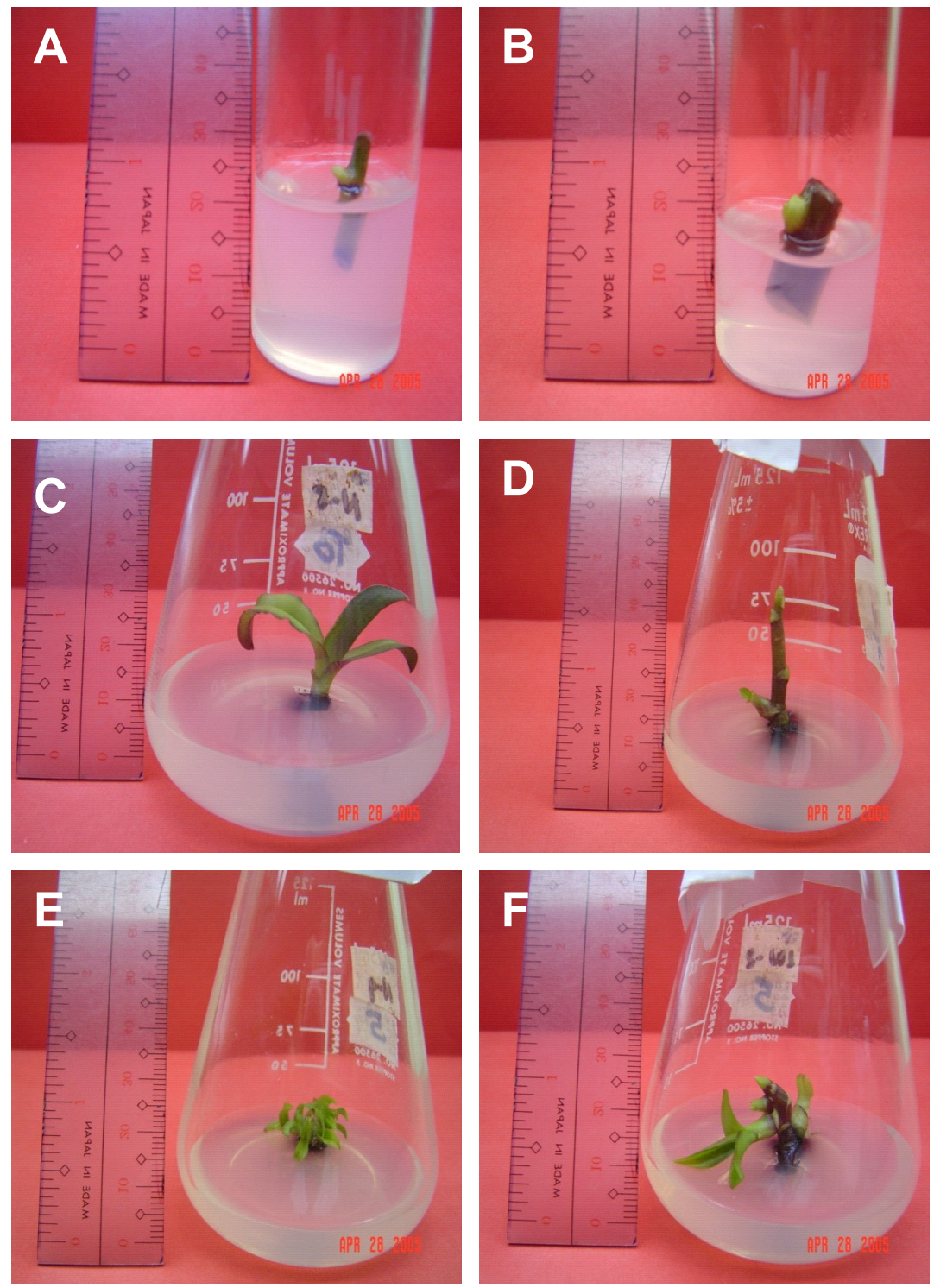

Figure 2. In vitro regeneration of shoots from flower stalk explants of P. amabilis showing emergence of dormant buds from local variety (A) and hybrid (B); shoots with vegetative (C) and reproductive growth pattern and (D); multiple adventitious shoots of local variety (E) and hybrid (F). 
$80 \%$ of the shoots had vegetative growth pattern, $15-25 \%$ were of reproductive pattern and 5\% were dormant. Increasing the concentration of BAP to $10 \mathrm{mg} /$ 1 correspondingly increased the formation of shoots from both $P$. amabilis variety and hybrid. In the present study, the elongation of flower stalk buds was most noticeable in the hybrid 'Temple Cloud' (25\%) compared to the local variety $(15 \%)$ (Table 2). The appearance of second inflorescence inhibited plantlet formation. However, this can be overcome by frequent transfer of shoots in fresh medium where new shoots may developed at the lower most node of the inflorescence.

Generally, shoots with vegetative growth pattern showed high capability for further shoot production (Fig. 2E, F). Eighty percent of vegetative shoot cultures from $P$. amabilis variety and $35 \%$ of hybrid 'Temple' produced multiple shoots in medium containing $5 \mathrm{mg} / 1 \mathrm{BAP}, 0.1 \mathrm{mg} / \mathrm{lAA}, 30 \mathrm{mg} / \mathrm{l}$ thiamine, $20 \%(\mathrm{v} / \mathrm{v})$ coconut water, and $20 \mathrm{~g} / \mathrm{l}$ sugar (Fig. 3). Increasing the concentration of BAP to $10 \mathrm{mg} / 1$ reduced the percentage of adventitious shoot proliferation in P. amabilis variety but, increased this in the hybrid 'Temple'. This suggests a higher BAP requirement for shoot proliferation of the hybrid compared to the local variety. Lower BAP concentration $(2 \mathrm{mg} / \mathrm{l})$ resulted to very low percentage of proliferating shoots while, the medium lacking BAP or control did not induce shoot proliferation.

The regenerated shoots with reproductive growth pattern showed very low capacity for adventitious shoot formation. Only a few (10-20\%) of these structures were produced in the medium containing BAP (data not shown). This phenomenon needs to be further studied to determine the factors that enhance adventitious shoot formation from reproductive shoot cultures.

\section{In vitro rooting and establishment of flower stalk-derived plantlets}

The stalk bud-derived plantlets of $P$. amabilis resembled the donor plants and produced roots in agar-solidified VW medium lacking plant growth regulators after 50-55 days of culture. IBA was no longer necessary for rooting. The plantlets of the local variety $(60 \%)$ rooted easily compared to the hybrid (20\%) (Fig. 4A, B). Generally, the plantlets regenerated from the local variety exhibited faster shoot growth and development compared to the hybrids in 


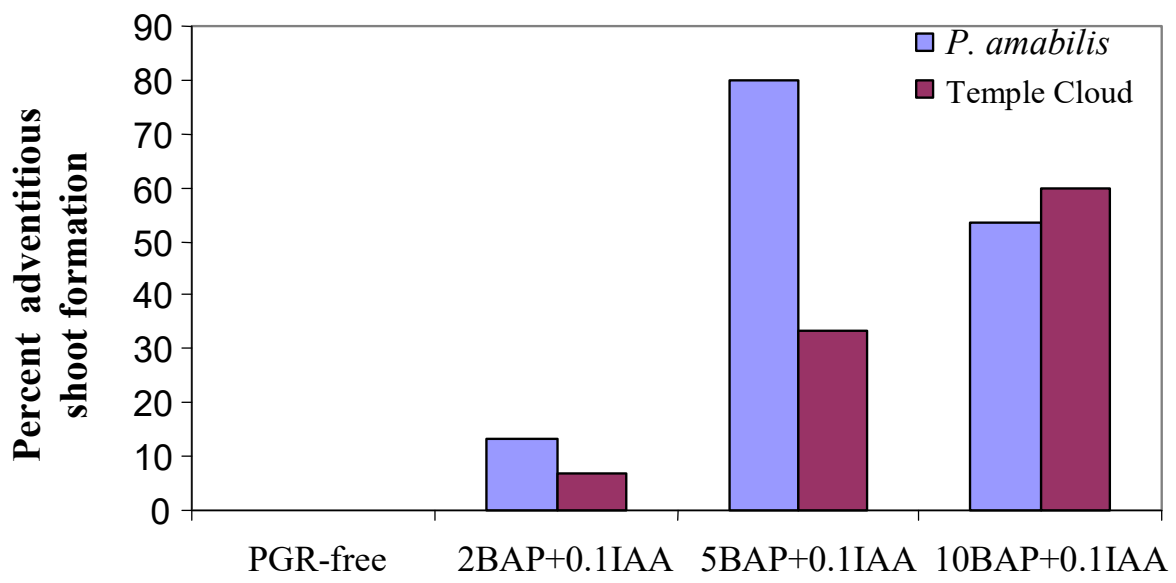

\section{Treatments (mg/l)}

Figure 3. Percent of flower stalk-derived shoot cultures of P. amabilis variety and hybrid that produced multiple adventitious shoots in VW medium supplemented with combinations of BAP and IAA.
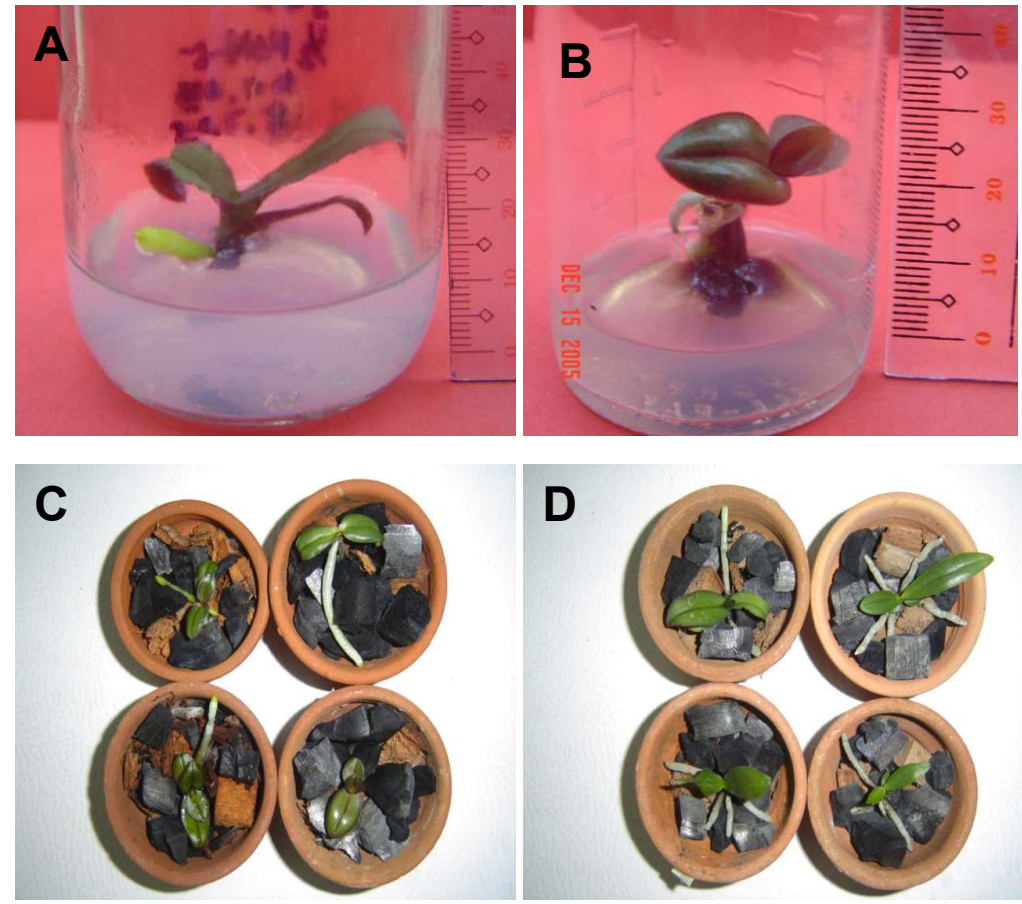

Figure 4. In vitro rooting of stalk bud-derived shoots of $P$. amabilis in plant growth regulator-free VW medium, and transplanting of plantlets in pots containing wooden charcoal. A\& D, local variety; B \& C, hybrid 'Temple Cloud'. 
vitro. These plantlets needed to be hardened to prevent water loss and desiccation of plantlets upon immediate exposure to ordinary condition. Prolonged hardening increased the survival of plantlets after transplanting in thumb pots containing wooden charcoal (Fig. 4C, D).

Thus, the present study succeeded in producing plantlets from flower stalk cuttings of $P$. amabilis variety and hybrid by overcoming persistent contamination and optimizing culture medium. Furthermore, proliferation of multiple adventitious shoots was also achieved by using stalk bud-derived shoots as explants. The present protocol can be used to clonally propagate Phalaenopsis species.

\section{CONCLUSION}

Regeneration of plantlets from flower stalk explants of P. amabilis variety and hybrid was demonstrated in this study. The problem of persistent contamination of stalk explants was overcome by a decontamination method employing ethyl alcohol, chlorine bleach and streptomycin. Successful regeneration of shoots from flower stalk buds was obtained in agar-solidified VW medium containing $5 \mathrm{mg} / 1 \mathrm{BAP}, 30 \mathrm{mg} / 1$ thiamine, $20 \%$ coconut water, and $2 \%$ sugar. The regenerated shoots exhibited three growth patterns, namely; vegetative, reproductive and dormant. The vegetative shoot had higher regeneration capacity compared to the reproductive or dormant shoot. The flower stalk derived-shoots were morphologically normal and rooted in plant growth regulator-free VW medium. These developed into healthy plantlets when potted in wooden charcoal and hardened in the greenhouse.

\section{LITERATURE CITED}

ARDITTI, J. and R. EARNST. 1993. Micropropagation of orchids. New York: Wiley. pp.467-520.

ARDITTI, J. and R. ERNST. 1994. Micropropagation of orchids. John Wiley and Sons, Inc. New York

ARMSTRONG, H. 2001. Orchids still tricky despite breeding improvements. Flower Tech. 4 (3):34-36 
BELAMINO, M. M. and M. MII. 2000. Agrobacterium-mediated genetic transformation of a Phalaenopsis orchid. Plant Cell Reports, 19:435 - 442

GRIESBACH, R.J. 2002. Development of Phalaenopsis orchids for the mass-market. In: J. Janick and A. Whipkey (eds.), Trend in new crops and uses. ASHS, pp.458-465

ICHIHASHI, S. 1992. Lindleyana 7:208-215 Micropropagation of Phalaenopsis and Doritaenopsis by culturing shoot tips of flower stalk buds. Plant Cell Rep,13:711

ISHII, Y., T. TAKAMURA, M. GOI, M. TANAKA. 1998. Callus induction of somatic embryogenesis of Phalaenopsis. Plant Cell Reports 17:446-450

LOPEZ, W. D. 2005. Influence of culture medium, antibiotic supplement and type of explant on the growth and development shoot tip explants of banana (Musa sapientum) cv. 'Lakatan'. Unpublished manuscript, LSU, Visca, Baybay, Leyte

NEELE, A.M. JR. 1993. The cutflower industry in the Philippines. National Floriculture Convention, Davao City, 1996

PARK, Y.S., S. KAKUTA, A. KANO, and M. OKABE. 1996. Efficient propagation of protocorm-like bodies of Phalaenopsis in liquid medium. Plant Cell Tissue and Organ Culture, 45:79-85

PARK, S-Y, H. N. MURTHY, and K. Y. PAEK. 2002. Rapid propagation of phalaenopsis from floral stalk-derived leaves. In Vitro Cell. Dev. Biol.-Plant 38:168-172

SARMIENTO, L. G. 2005. Regeneration of plantlets from flower stalk cuttings of Phalaenopsis amabilis. Unpublished manuscript, LSU, Visca, Baybay, Leyte

TANAKA, M.. 1992. Micropropagation of Phalaenopsis spp. In: Biotechnology in Agriculture and Forestry, (ed.) V.P. S. Bajaj. 20; 246-258. Springler-Verlag Heidelberg

TOKUHARA, K. and M. MII. 1993. Micropropagation of Phalaenopsis and Doritaenopsis by culturing shoot tips of flower stalk buds. Plant Cell Rep,13:711

VACIN, E. K. and F.W. WENT. 1949. Some of the ph changes in nutrient solution. Bot. Gaz., 110:605-613 